\title{
Greetings from the New Editor-in-Chief
}

\author{
Jeong-Hyun Hwang \\ Editor-in-Chief, Brain Tumor Research and Treatment
}

It is a great honor for me to take over the position of Editorin-Chief of the Brain Tumor Research and Treatment (BTRT), following the former Editor-in-Chief, Professor Heon Yoo of National Cancer Center. I feel privileged to thank Professor Yoo, the first Editor-in-Chief of the journal, for his excellent work and commitment to BTRT for five long years.

BTRT has evolved from the Journal of Korean Brain Tumor Society, which published its first edition in 2002. BTRT currently is the official journal of The Korean Brain Tumor Society (KBTS), The Korean Society for Neuro-Oncology (KSNO), and The Korean Society for Pediatric Neuro-Oncology (KSPNO). The aim of BTRT is to publish the highest quality papers which are dedicated to the advancement of care of patients with central nervous system tumors. BTRT was launched in April 2013, published twice a year electronically and in print. It covered the whole field of neuro-oncology from molecular genetics to surgical neuro-oncology and has established itself as a major journal in the field of central nervous system tumor treatment and research. All of the articles in this journal are indexed in PubMed Central, PubMed, KoreaMed, KoreaMed Synapse, and KRF/ KCI.

Although the BTRT has made a remarkable advancement for last 5 years since its first publication, the result falls short of our expectation. It is regrettable that we still did not reach the aim, to be enlisted as the SCI(E) class, we founded five years ago when the inaugural issue was introduced. We have welcomed submissions from all over the world to become an international journal, but small portions of submitted papers were still from outside of Korea.

It is now my honorable duty to lead the journal along with the outstanding members of Editorial Board and International Editorial Board. It will be my aim to increase the visibility and attractiveness of BTRT. We courteously welcome the new members of Editorial Board and Review Board. Together we will continuously work hard to improve the quality of papers and reduce the turn-around time for manuscripts. We will try to provide rapid, unbiased and meaningful peer-review and editorial decisions in time. I cordially invite authors to submit precious original and first-hand papers as well as review articles, which will help to achieve our goal of maintaining high quality paper publication. In parallel, further changes will take place in journal format in line with rapidly progressing scientific environment and reader's demand. I hope that BTRT serves as a platform to share the information among brain tumor investigators of diverse scientific field and provide opportunities for interdisciplinary research.

In closing, I would like to express my appreciation for the members of Editorial Board and International Editorial Board who have helped enthusiastically to improve the quality of $B T R T$. I would also like to offer special thanks to Editors, Review Board members and a secretory of $B T R T$ for their respectful dedication.

This is an Open Access article distributed under the terms of the Creative Commons Attribution Non-Commercial License (http://creativecommons.org/licenses/by-nc/4.0) which permits unrestricted non-commercial use, distribution, and reproduction in any medium, provided the original work is properly cited.

Copyright $\odot 2017$ The Korean Brain Tumor Society, The Korean Society for NeuroOncology, and The Korean Society for Pediatric Neuro-Oncology 